\title{
A FRICTION METER FOR DETERMINING THE COEFFI- CIENT OF KINETIC FRICTION OF FABRICS
}

\author{
By Edwin C. Dreby ${ }^{1}$
}

\section{ABSTRACT}

A friction meter is described, and its application to the evaluation of the smoothness of a wide variety of fabries is discussed. The ruggedness, sensitivity, and ease of operation of the instrument make it suitable for the routine testing of fabrics, the evaluation of finishing agents, and the control of finishing processes.

\section{CONTENTS}

Page

I. Introduction

II. Description and use of the friction meter

III. Calibration of the friction meter

IV. Factors affecting the coefficient of kinetic friction .............. 240

V. Discussion of results of measurements with the friction meter

VI. Applications of the frietion meter

VII. References _..... 246

\section{INTRODUCTION}

The frictional properties of textile fibers, yarns, and fabrics have to be taken into consideration by both manufacturers and users of fabrics. Fabric smoothness, "sheen," "creep," and wear are very important characteristics associated with the frictional properties of fabrics. The development of new fibers and finishing agents for fabrics creates a need for adequate means for evaluating their characteristics. To this end an investigation was undertaken jointly by the American Society for Testing Materials and the National Bureau of Standards for the development of methods for the evaluation of textile finishes. The work reported in this paper is concerned principally with the relation of frictional properties to the smoothness of fabrics and to "hand" or feel, in general. The friction meter described in this paper was developed for determining the coefficient of friction of fabrics. The device meets the requirements of ruggedness, sensitivity, and ease of operation desired of an instrument for routine textile testing.

One of the earliest recorded investigations of the frictional characteristics of fabrics was that of Rennie [1], ${ }^{2}$ who measured the resistance to sliding and abrasion of several wool fabrics. Rennie used the sliding-

1 Formerly Research Associate at the National Bureau of Standards, representing the American Society for Testing Materials.

2 Figures in brackets indicate the literature references at the end of the paper. 
block method, in which a fixed block is covered with one piece of the fabric to be tested and a weighted movable block is covered with another piece. The force just sufficient to overcome the resistance to sliding of one block on the other is then determined.

Two recent investigators have studied fabric friction and its relation to the slipperiness and smoothness of fabrics in the hands. Mercier [2] used the inclined-plane method in which a block covered with one piece of the fabric rests upon a sloping surface covered with another piece of the fabric. The tangent of the angle that the sloping surface makes with the horizontal when the block will just start to slide is taken to be the coefficient of friction. Morrow [3] developed a method for determining the coefficient of kinetic friction, in which a strip of the fabric was fastened on the rim of a wheel that was rotated at constant speed. Another strip of the cloth or some other material was mounted on a block that rested on the rim under known load. The frictional force was balanced by weights. Morrow determined the coefficient of kinetic friction of a fabric both against itself and against other surfaces.

The friction meter was devised to overcome a disadvantage common to the methods utilized by the previous investigators, namely that of having to balance the frictional force by varying the applied force by increments. Such a procedure requires numerous trials before the frictional force is balanced correctly. This disadvantage not only makes the measurement tedious but it also leads to unsatisfactory results, particularly for fabrics having a coefficient of static friction and a coefficient of kinetic friction of widely different magnitudes. With the friction meter, the frictional force is balanced continuously by spring tension so that all fabrics may be tested with a simple and identical technique. In addition the device has the ruggedness of construction and simplicity of design desired in a laboratory testing instrument.

In the present paper the construction and operation of the friction meter is described, and various factors affecting the measurement of the coefficient of friction and the relation of the coefficient of friction to the smoothness and hand of fabrics are discussed.

\section{DESCRIPTION AND USE OF THE FRICTION METER}

A sketch of the friction meter is given in figure 1. A horizontal table about 6 inches square, having a smooth surface, is located between a torsion element and a drum. The torsion element has a clamp for attaching one of a pair of fabric specimens required for a test. Deflections of the torsion element are indicated on a dial gage. The drum is provided with a clamp for attaching the other fabric specimen to it and a crank for winding the specimen on the drum. A metal block weighing 1 pound and having a lower surface 10 square inches in area ( 3 inches by $3 \frac{1}{3}$ inches) is provided ${ }^{3}$ to subject the specimens to load.

In making a test, two specimens about 10 inches long and $3 \frac{1}{2}$ inches wide are cut from the fabric with the long dimension of each specimen in the direction of the fabric for which the coefficient of friction is

\footnotetext{
${ }^{3}$ Drawings showing the details of construction of the friction meter may be obtained from the National Bureau of Standards. A special committee of the American Society for Testing Materials has arranged for the manufacture of this machine for sale. Further information can be obtained from the chairman of the Special Committee, George A. Slowinske, E. I. du Pont de Nemours \& Co., Inc., P. O. Box 386, Wilmington, Del.
} 
desired. An end of one specimen is fastened in the clamp on the drum so that the fabric lies face up on the table of the instrument. An end of the other specimen is fastened in the clamp on the torsion element so that it lies face down on the specimen attached to the drum. The weight is placed centrally on top of the test specimens. The crank is then turned at a steady rate of approximately 30 revolutions per minute, thus drawing the lower specimen from under the upper one at a speed approximating $2 \frac{1}{2}$ feet per minute. The specimen is drawn through until its free end reaches the back edge of the weight and then,

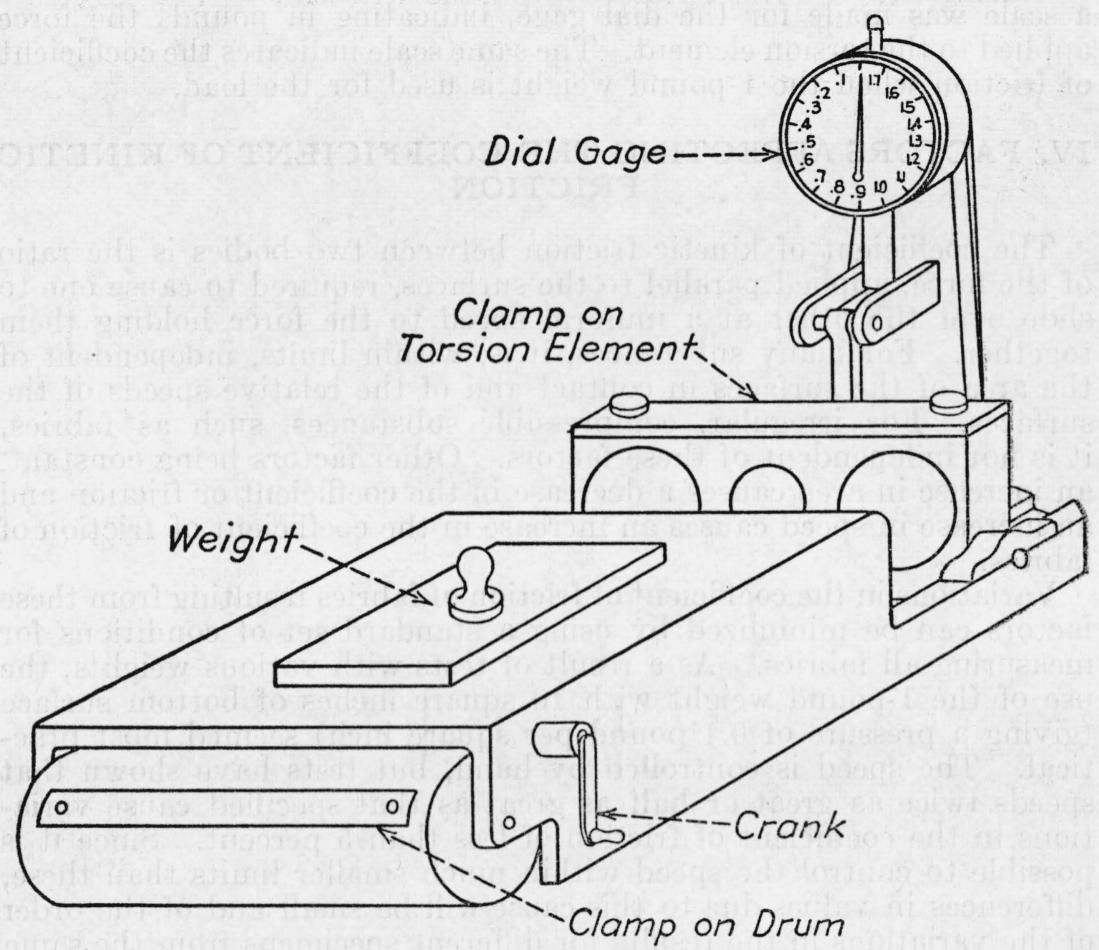

Figure 1.-Friction Meter.

without unclamping, the specimens are put back in their original positions and the process is repeated. The constant or nearly constant value indicated on the dial of the gage the second time the lower specimen is withdrawn is noted. This is taken to be the coefficient of kinetic friction of the fabric sliding on itself when the scale on the dial indicates the frictional force in pounds, as provided below, and the 1-pound load is used. The average of the results obtained by testing two pairs of specimens is sufficiently duplicable for most purposes, as is shown later.

\section{CALIBRATION OF THE FRICTION METER}

The friction meter was calibrated in a simple manner. A fine string was fastened in the clamp on the torsion element and passed over a low-friction pulley placed in front of the instrument so that it just cleared the table of the instrument. A pan for holding weights was 
fastened to the free end of the string. Deflections of the dial gage were noted for a series of loads from 0 to 2 pounds, successive loads differing by $1 / 4$-pound increments. By applying slight hand pressure to the torsion element, deflections for specific loads were noted as the equilibrium point was approached from higher and lower values. With the well-lubricated, low-friction pulley that was used, the differences between the deflections for the two directions of approach were very small. The mean was taken. Within the range of calibration there was a linear relationship between the deflections of the torsion element and the applied loads. From the calibration obtained, a scale was made for the dial gage, indicating in pounds the force applied to the torsion element. The same scale indicates the coefficient of friction when the 1-pound weight is used for the load.

\section{FACTORS AFFECTING THE COEFFICIENT OF KINETIC FRICTION}

The coefficient of kinetic friction between two bodies is the ratio of the force, applied parallel to the surfaces, required to cause one to slide over the other at a uniform speed to the force holding them together. For many substances, it is, within limits, independent of the area of the surfaces in contact and of the relative speeds of the surfaces. For irregular, compressible substances, such as fabrics, it is not independent of these factors. Other factors being constant, an increase in area causes a decrease in the coefficient or friction and an increase in speed causes an increase in the coefficient of friction of fabrics.

Variations in the coefficient of friction of fabrics resulting from these factors can be minimized by using a standard set of conditions for measuring all fabrics. As a result of tests with various weights, the use of the 1-pound weight with 10 square inches of bottom surface (giving a pressure of 0.1 pound per square inch) seemed most practical. The speed is controlled by hand, but tests have shown that speeds twice as great or half as great as that specified cause variations in the coefficient of friction of less than 5 percent. Since it is possible to control the speed within much smaller limits than these, differences in values due to this cause will be small and of the order of the variations in the results for different specimens from the same fabric, which are from 1 percent to 4 percent, depending upon the magnitude of the coefficient of friction.

Variables that might influence the results because of improper placing of the weight were investigated. Placing the weight at different positions other than the central position, dropping it in place, adding an additional load and removing it before the test, permitting the weight to rest on the specimens for different time intervals before making the test, and placing the weight on the specimen with a mechanical device to avoid impact, resulted in no more scattering of the results of individual tests than was obtained with the specified technique.

Several types of surfaces were tried in an attempt to establish a standard surface against which all fabrics may be measured. These included different fabric surfaces, two metal surfaces with different degrees of polish, and two leather surfaces. The coefficients of friction of some of these surfaces were not sufficiently constant or reproducible, and the range of results for series of fabrics tested against 
a common surface was much smaller than the range when tested against their own surface. The greater sensitivity of the fabric against fabric method of measurement and the advantage of having a fresh surface for each measurement led to the testing of the fabric against itself in the studies made with the friction meter.

Figure 2 shows how the values of the coefficient of friction vary during the measurement and on successive remeasurements of a pair of specimens of cotton percale. At the start of relative motion a very high reading is obtained. This value varies over a considerable range for different specimens from the same fabric, being affected by

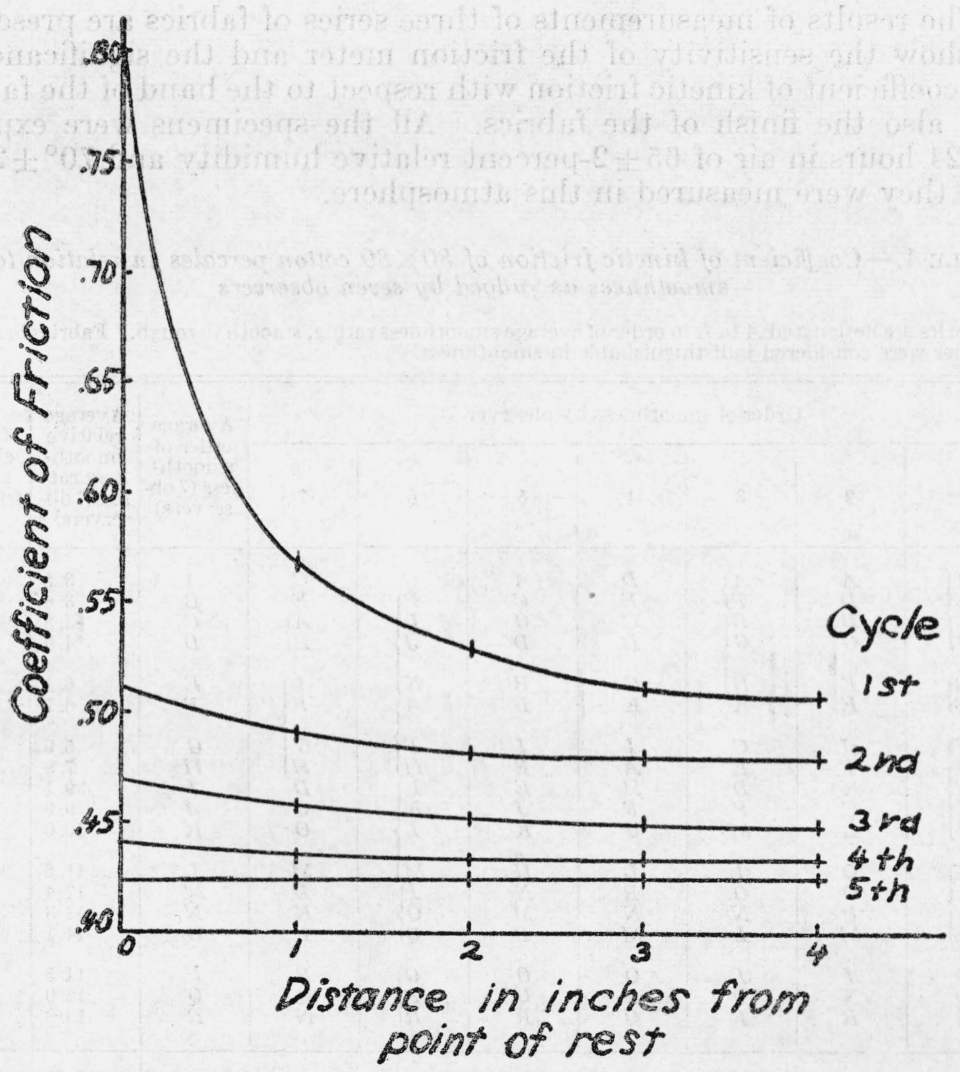

FraURe 2.-Variations in coefficient of friction during course of tests on an $80 \times 80$ cotton percale.

the manner in which the weight is placed on the specimens and by small differences between the specimens. As soon as relative motion of the specimens is begun, the value drops rapidly and after a relative movement of 2 inches the value is almost constant. On remeasuring the specimen, the value is at first approximately the same as that near the end of the previous measurement. It drops to a more or less steady value, which is lower than that obtained in the first test. When the measurements are repeated further, with the same surfaces, the coefficient of kinetic friction drops slowly and continuously. This change in the coefficient of friction probably results from lining 


\section{Journal of Research of the National Bureau of Standards}

up the projecting fibers and matting them into a smoother, more compact surface. The values of the coefficient of friction of cotton percales observed in the second test were the earliest values that were reproducible. Other fabrics gave results varying no more than these, and some fabrics, like smooth rayon twills or satins, gave results varying much less. Accordingly, the procedure of observing the coefficient during the second test was used for all fabrics.

\section{DISCUSSION OF RESULTS OF MEASUREMENTS WITH THE FRICTION METER}

The results of measurements of three series of fabrics are presented to show the sensitivity of the friction meter and the significance of the coefficient of kinetic friction with respect to the hand of the fabrics and also the finish of the fabrics. All the specimens were exposed for 24 hours in air of $65 \pm 2$-percent relative humidity and $70^{\circ} \pm 2^{\circ} \mathrm{F}$, and they were measured in this atmosphere.

\section{$\mathrm{T}_{\mathrm{ABLE}}$ 1.-Coefficient of kinetic friction of $80 \times 80$ cotton percales in relation to their smoothness as judged by seven observers}

Fabrics are designated $A$ to $R$ in order of average smoothness rating, smooth to rough. Fabrics bracketed together were considered indistinguishable in smoothness.

\begin{tabular}{|c|c|c|c|c|c|c|c|c|c|}
\hline \multicolumn{7}{|c|}{ Order of smoothness by observer } & \multirow{2}{*}{$\begin{array}{l}\text { A verage } \\
\text { order of } \\
\text { smooth- } \\
\text { ness (7 ob- } \\
\text { servers) }\end{array}$} & \multirow{2}{*}{$\begin{array}{l}\text { Average } \\
\text { relative } \\
\text { smooth- } \\
\text { ness rat- } \\
\text { ing ( } 7 \text { ob- } \\
\text { servers) a }\end{array}$} & \multirow{2}{*}{$\begin{array}{l}\text { Coeffi- } \\
\text { cient of } \\
\text { kinetic } \\
\text { friction b }\end{array}$} \\
\hline 1 & 2 & 3 & 4 & 5 & 6 & 7 & & & \\
\hline $\left.\begin{array}{l}A \\
B \\
C \\
J\end{array}\right\}$ & $\begin{array}{l}A \\
D \\
B \\
G\end{array}$ & $\left.\begin{array}{c}A \\
F \\
B \\
G\end{array}\right\}$ & $\begin{array}{l}D \\
E \\
C \\
B\end{array}$ & $\begin{array}{l}A \\
C \\
G \\
D\end{array}$ & $\left.\begin{array}{l}C \\
B \\
D \\
J\end{array}\right\}$ & $\left.\begin{array}{l}C \\
E \\
A \\
B\end{array}\right\}$ & $\begin{array}{l}A \\
B \\
C \\
D\end{array}$ & $\begin{array}{l}3.5 \\
3.6 \\
3.8 \\
4.9\end{array}$ & $\begin{array}{r}0.49 \\
.49 \\
.39 \\
.39\end{array}$ \\
\hline $\left.\begin{array}{l}D \\
E\end{array}\right\}$ & $\begin{array}{l}F \\
E\end{array}$ & $\stackrel{H}{K}$ & $\stackrel{G}{K}$ & $\begin{array}{l}B \\
L\end{array}$ & $\begin{array}{l}N \\
A\end{array}$ & $\begin{array}{l}I \\
F\end{array}$ & $\begin{array}{l}E \\
F\end{array}$ & $\begin{array}{l}6.1 \\
6.7\end{array}$ & $\begin{array}{l}.45 \\
.53\end{array}$ \\
\hline $\left.\begin{array}{c}F \\
G \\
H \\
I \\
M\end{array}\right\}$ & $\begin{array}{l}H \\
I \\
K \\
C \\
L\end{array}$ & $\begin{array}{l}C \\
E \\
D \\
P \\
M\end{array}$ & $\begin{array}{l}I \\
A \\
H \\
F \\
J\end{array}$ & $\begin{array}{l}I \\
F \\
E \\
J \\
K\end{array}$ & $\begin{array}{c}F \\
H \\
E \\
K \\
L \\
\}\end{array}$ & $\begin{array}{l}G \\
H \\
D \\
J \\
O\end{array}$ & $\begin{array}{l}G \\
H I \\
I \\
J \\
K\end{array}$ & \begin{tabular}{r|}
6.9 \\
7.8 \\
9.1 \\
9.9 \\
10.0
\end{tabular} & $\begin{array}{l}.36 \\
.46 \\
.45 \\
.40 \\
.42\end{array}$ \\
\hline $\left.\begin{array}{c}K \\
L \\
N \\
P\end{array}\right\}$ & $\begin{array}{l}Q \\
O \\
P \\
M\end{array}$ & $\begin{array}{l}I \\
O \\
N \\
L\end{array}$ & $\begin{array}{l}L \\
R \\
N \\
M\end{array}$ & $\begin{array}{l}H \\
N \\
M \\
P\end{array}$ & $\left.\begin{array}{c}M \\
I \\
O \\
Q\end{array}\right\}$ & $\begin{array}{l}M \\
L \\
K \\
P\end{array}$ & $\begin{array}{l}L \\
M \\
N \\
O\end{array}$ & \begin{tabular}{l|}
11.6 \\
12.4 \\
13.3 \\
14.1
\end{tabular} & $\begin{array}{l}.43 \\
.46 \\
.53 \\
.50\end{array}$ \\
\hline $\begin{array}{l}O \\
\stackrel{O}{ } \\
R\end{array}$ & $\begin{array}{l}J \\
N \\
R\end{array}$ & $\begin{array}{l}J \\
Q \\
R\end{array}$ & $\begin{array}{l}O \\
P \\
Q\end{array}$ & $\begin{array}{l}O \\
Q \\
R\end{array}$ & $\left.\begin{array}{l}G \\
P \\
R\end{array}\right\}$ & $\begin{array}{l}R \\
Q \\
N\end{array}$ & $\begin{array}{l}P \\
Q \\
R\end{array}$ & $\begin{array}{l}14.5 \\
16.0 \\
16.9\end{array}$ & $\begin{array}{l}.51 \\
.60 \\
.55\end{array}$ \\
\hline \multicolumn{8}{|c|}{ Average mean deviation } & \pm 2.35 & \pm 0.009 \\
\hline
\end{tabular}

a Obtained by assigning numerical ratings of 1 to 18 to the fabrics in the order in which they were placed by the observers (from smooth to rough). The numbers for fabrics bracketed together were then averaged, and all fabries in the braciket were given this average rating.

$b$ A verage of 2 determinations.

A series of eighteen $80 \times 80$ cotton percales, representing the products of 10 different manufacturers, were graded with respect to their relative smoothness by each of 7 textile experts. The fabrics were then numbered from 1 to 18 in the order in which they were placed by each expert, from smooth to rough, and these numbers were used as numerical ratings. The numbers of fabrics which were considered indistinguishable by an expert were averaged, and the average value was taken to be the numerical rating of those fabrics. The seven 
individual relative ratings thus obtained for each fabric were averaged to give an average relative smoothness rating. The data and results are given in table 1 . The mean deviation of the seven individual ratings was computed for each fabric. The average of these mean deviations was \pm 2.35 units of rating.

The coefficients of kinetic friction of these fabrics were determined for duplicate pairs of specimens. The average mean deviation calculated as above was \pm 0.009 unit of the coefficient of kinetic friction. The data are given in table 1.

The ratio of the spread of values obtained by each method to their average mean deviation is an indication of the number of distinct groups into which these fabrics might be divided by the methods of measurement. The ratio for the friction meter is about 27 , for the smoothness ratings only 6 . The friction meter is thus quite sensitive to differences in the fabrics. This was found to be true for other fabrics, and measurements indicated that two pairs of specimens of most fabrics would give a reliable result.

The correlation between the order of the eighteen $80 \times 80$ cotton percales determined by the tactual method and by the friction-meter method was computed by the method of Kendall. ${ }^{4}$ It was 35 to 41 percent, depending upon the order of ranking of the fabrics whose coefficients of friction are the same. According to this statistical test, no clear correlation is indicated. It must be concluded that the coefficient of friction is not the only property of a fabric contributing to its smoothness.

Separate portions of an $80 \times 80$ and of a $68 \times 72$ print cloth were treated with different concentrations of each of two finishing agents. This method of treatment produced only small differences in the physical properties of the fabrics. Under these conditions there was a direct relationship between the coefficient of friction and the relative differences in smoothness, as shown by the results in table 2 .

TABLE 2.-Coefficients of kinetic friction of $80 \times 80$ and $68 \times 72$ cotton print cloth treated with different concentrations of two finishing agents

\begin{tabular}{|c|c|c|c|}
\hline \multirow{2}{*}{ Fabric treatment } & \multicolumn{2}{|c|}{$\begin{array}{l}\text { Coefficient of ki- } \\
\text { netic friction }\end{array}$} & \multirow{2}{*}{$\begin{array}{l}\text { Tactual } \\
\text { smooth- } \\
\text { ness, (1) } \\
\text { rough to } \\
\text { (4) smooth }\end{array}$} \\
\hline & $80 \times 80$ & $68 \times 72$ & \\
\hline $\begin{array}{l}\text { Untreated } \\
1.0 \% \text { of finish } A \\
2.0 \% \text { of finish } A \\
\text { Untreated } A \\
1.0 \% \text { of finish } B \\
2.5 \% \text { of finish } B\end{array}$ & $\begin{array}{r}0.61 \\
.56 \\
.53 \\
.52 \\
.61 \\
.54 \\
.54 \\
.55\end{array}$ & $\begin{array}{r}0.64 \\
.60 \\
.59 \\
.58 \\
.64 \\
.60 \\
.60 \\
.61\end{array}$ & $\begin{array}{l}1 \\
2 \\
3 \\
4 \\
1 \\
4 \\
3 \\
2\end{array}$ \\
\hline
\end{tabular}

Various relations between flexibility and compressibility, the two other principal properties of a fabric affecting the judgment of hand, and the coefficient of friction which might give an evaluation of

1 The Kendall coefficient of correlation between two series of rankings is given by the equation $2 \Sigma / n(n-1)$, where $n$ is the number of members ranked, and $\Sigma$ is computed as follows: The members are put in objective order in the one series, which then determines the corresponding order of the rankings for the other series. Each member in turn of the latter sequence of rankings is compared with succeeding members in the sequence. Those pairs in the correet order are given a value of +1 ana those in the inverted order are given a value of -1 . The sum of these values is denoted $\Sigma$. The methor is described in detail by Schwarz and Winn in "Technical Evaluation of Textile Finishing Treatments. III. Use of Rank Correlation for Comparison of Data." Am. Dyestuff Reptr. 29, 400 (1940); Textile Research 10, 453 (1940). $548900-43-4$ 


\section{Journal of Research of the National Bureau of Standards}

smoothness were investigated without success. Thus, except in such series as those illustrated above, the coefficient of friction may not be a direct indication of the smoothness of a fabric.

The usefulness of the coefficient of friction for evaluating fabric finishes is further illustrated by the results of measurements on a series of warp-knit rayon dress fabrics that were prepared by treating separate portions of the same grey fabric with 1-percent solutions of nine commercial finishing agents. Each finishing agent produced different effects with respect to the smoothness, softness, and pliability of the fabrics. The smoother, the softer, and the more pliable these particular fabrics, the more desirable they were for their intended use. The fabrics are listed in table 3 , in groups, in the order of decreasing desirability as determined by three experts. The coefficients of kinetic friction obtained with the friction meter are given, together with values for flexibility and compressibility. Since the properties affecting the hand of these fabrics were integrated mentally by the experts evaluating them, and since a study of the results of the physical measurements indicated that a good quality in one property compensated for a poorer one in another, the results of the physical measurements were combined in the simplest ratio consistent with their relationship to the desirability of these fabrics. As shown in the table, the ratio combining all three measured values gives a better indication of the desirability of these fabrics than any one of the measured values alone or the ratio of the values of compressibility and flexibility.

TABLE 3.-Correlation between the desirability of finish and several properties of warp-knit rayon dress fabrics

\begin{tabular}{|c|c|c|c|c|c|c|}
\hline 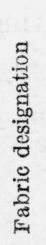 & 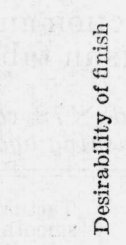 & 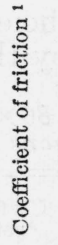 & 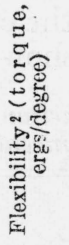 & 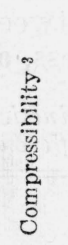 & 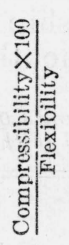 & 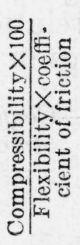 \\
\hline $\begin{array}{l}A \\
B \\
C \\
D \\
D \\
E \\
F \\
G \\
H \\
I \\
I\end{array}$ & $\left\{\begin{array}{l}\text { Excellent } \\
\text { Good } \\
\text { Fair } \\
\text { Poor }\end{array}\right.$ & $\begin{array}{l}0.39 \\
.43 \\
.40 \\
.42 \\
.44 \\
.46 \\
.48 \\
.41 \\
.44\end{array}$ & $\begin{array}{l}19.6 \\
22.1 \\
20.9 \\
21.6 \\
21.6 \\
20.9 \\
19.4 \\
26.7 \\
24.4\end{array}$ & $\begin{array}{l}0.278 \\
.254 \\
.246 \\
.246 \\
.266 \\
.261 \\
.241 \\
.227 \\
.227\end{array}$ & $\begin{array}{l}1.42 \\
1.15 \\
1.18 \\
1.14 \\
1.23 \\
1.25 \\
1.24 \\
0.86 \\
0.93\end{array}$ & $\begin{array}{l}3.64 \\
2.67 \\
2.94 \\
2.71 \\
2.80 \\
2.71 \\
2.59 \\
2.07 \\
2.11\end{array}$ \\
\hline
\end{tabular}

1 Friction meter.

2 Schiefer flexometer [4].

${ }^{3}$ Compression meter [5]. The quantities are proportional to the volume lost by the fabric upon changing the pressure on the fabric from 0.05 to. 0.45 pound per square inch.

This suggests the possibility that values of the coefficient of friction, flexibility, and compressibility may give a means of distinguishing the differences of hand of series of similarly constructed fabrics. The choice of a method for combining the numerical values for these properties will depend upon the character of the hand desired, for the desired character of hand varies with such factors as the purpose for which the fabric is intended and current fad. Once a method is 
devised for a given class of fabrics, however, then the hand of other fabrics of the class presumably may be determined from the results of measurements of the frictional, flexural, and compressional properties.

The studies on these and numerous other groups of fabrics lead to the following conclusions: The coefficient of friction contributes to the evaluation of smoothness but in itself is not always a measure of smoothness. For similar fabrics, where other properties are approximately the same, the fabric with the lower coefficient of friction is the smoother. The coefficient of friction, when considered with other properties affecting the hand of fabrics, may lead to an over-all evaluation of hand. A knowledge of frictional characteristics is necessary for the specification of finish.

\section{APPLICATIONS OF THE FRICTION METER}

The friction meter has been applied to the testing of a wide variety of fabrics, including cotton percales, broadcloths, poplins, twills, and sateens; rayon crepes, twills, satins, and spun rayons of linen-like and challis-like finish; wool and mixed wool-rayon uniform shirtings and suitings; and knit fabrics including warp-knit rayon dress fabrics and silk and nylon hosiery. The ranges of values obtained for these fabrics are given in table 4.

TABLE 4.-Range of coefficient of kinetic friction of different types and constructions of fabrics

\begin{tabular}{|c|c|}
\hline Types and constructions & $\begin{array}{l}\text { Coefficient of } \\
\text { kinetic friction }\end{array}$ \\
\hline $\begin{array}{l}\text { Cotton: } \\
\quad 80 \times 80 \text { percales } \\
\quad 100 \times 60 \text { broadcloths. } \\
100 \times 40 \text { poplins } \\
\quad 68 \times 72 \text { twills. } \\
\quad 65 \times 110 \text { sateens. }\end{array}$ & $\begin{array}{l}0.35 \text { to } 0.60 \\
.33 \text { to } .56 \\
.40 \text { to } .58 \\
.39 \text { to } .67 \\
.34 \text { to } .49\end{array}$ \\
\hline 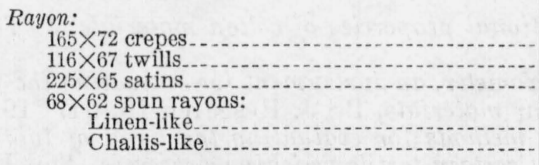 & $\begin{array}{l}0.24 \text { to } 0.36 \\
.14 \text { to } .21 \\
.24 \text { to } .33 \\
.66 \text { to } .74 \\
.68 \text { to } .74\end{array}$ \\
\hline $\begin{array}{l}\text { Wool and mixed wool-rayon: } \\
\text { Uniform shirtings....... } \\
\text { Uniform suitings........ }\end{array}$ & $\begin{array}{r}0.78 \text { to } 1.03 \\
.69 \text { to } 0.94\end{array}$ \\
\hline 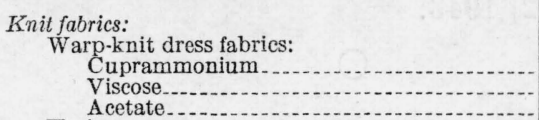 & $\begin{array}{l}0.39 \text { to } 0.48 \\
.26 \text { to } .30 \\
.34 \text { to } .52\end{array}$ \\
\hline $\begin{array}{l}\text { Hosiery: } \\
\text { 3-thread silk, } 30 \text { turns, } 42 \text { gage } \\
\text { 3-thread silk, high twist, } 42 \text { gage } \\
\text { 30-denier nylon, } 51 \text { gage. }\end{array}$ & $\begin{array}{l}0.28 \text { to } 0.50 \\
.26 \text { to } .36 \\
.22 \text { to } .31\end{array}$ \\
\hline
\end{tabular}

The coefficient of friction can be used to evaluate the effectiveness of different finishing treatments. Table 5 gives results for five groups of fabrics, showing the effect on the coefficient of friction of calendering, concentration of finishing agent, kind of finishing agent, fiber construction, and laundering. The effects are in general large and indicate the applicability of the friction meter in evaluating and controlling textile processing.

The friction meter can also be used to measure the coefficient of 


\section{Journal of Research of the National Bureau of Standards}

friction between two different fabric surfaces. Such measurements probably would be of use in evaluating the tendency of dresses and of underwear to "creep" when being worn.

TABLE 5.-Effect of different treatments on coefficient of kinetic friction

\begin{tabular}{|c|c|c|}
\hline & \multicolumn{2}{|c|}{$\begin{array}{l}\text { Coefficient of kinetic } \\
\text { friction }\end{array}$} \\
\hline $\begin{array}{l}\text { Calendering-80 }-80 \text { percale: } \\
\quad \text { Plain-finished. } \\
\text { Calendered. }\end{array}$ & \multicolumn{2}{|c|}{$\begin{array}{r}0.75 \\
.49\end{array}$} \\
\hline $\begin{array}{l}\text { Concentration of finishing agent- } 80 \times 80 \text { print cloth: } \\
\text { Untreated } \\
1.0 \% \text { finishing agent } \\
1.5 \% \text { finishing agent } \\
2.0 \% \text { finishing agent. }\end{array}$ & \multicolumn{2}{|c|}{$\begin{array}{l}.61 \\
.56 \\
.53 \\
.52\end{array}$} \\
\hline $\begin{array}{l}\text { Different finishing agents-silk stockings: } \\
\text { Untreated. } \\
\text { Softened } \\
\text { Delustered. }\end{array}$ & \multicolumn{2}{|c|}{$\begin{array}{l}.30 \\
.28 \\
.50\end{array}$} \\
\hline $\begin{array}{l}\text { Fiber composition-uniform suiting: } \\
\text { All wool } \\
50 \% \text { wool-50\% viscose }\end{array}$ & \multicolumn{2}{|c|}{$\begin{array}{l}.94 \\
.69\end{array}$} \\
\hline & $\begin{array}{l}\text { Starch } \\
\text { finish }\end{array}$ & $\begin{array}{l}\text { Semi- } \\
\text { permanent } \\
\text { finish }\end{array}$ \\
\hline $\begin{array}{l}\text { Laundering }-72 \times 60 \text { cotton sheeting: } \\
\text { Before laundering } \\
\text { After first laundering } \\
\text { After second laundering } \\
\text { After fifth laundering }\end{array}$ & $\begin{array}{r}0.47 \\
.79 \\
.77 \\
.73\end{array}$ & $\begin{array}{r}0.51 \\
.59 \\
.67 \\
.67\end{array}$ \\
\hline
\end{tabular}

\section{REFERENCES}

[1] George Rennie, Experiments on the friction and the abrasion of the surfaces of solids, Phil. Trans. Royal Soc. (London) 19, Article 15, 143 (1929). 1829

[2] A. A. Mercier, Coefficient of friction of fabrics, BS J. Research 5, 243 (1930) RP196.

[3] J. A. Morrow, The frictional properiies of cotton materials, J. Textile Inst. 22, T245 (1931).

[4] H. F. Schiefer, The Flexometer, an instrument for evaluating the flexural properties of cloth and similar materials, BS J. Research 10, 647 (1933) RP555.

[5] E. C. Dreby, Physical methods for evaluating the hand of fabrics and for determining the effects of certain textile finishing processes, Am. Dyestuff Reptr. 31, P497 (1942).

Washington, July 12, 1943. 
NATIONAL BUREAU OF STANDARDS, WASHINGTON, D. C.

Send me the Mathematical Tables marked X below. I enclose remittance ${ }^{1}$ to cover the cost.

\begin{tabular}{|c|c|c|c|c|}
\hline Mark X & Title of publication & $\begin{array}{l}\text { United States and } \\
\text { its possessions, } \\
\text { and countries ex- } \\
\text { tending franking } \\
\text { privilege }\end{array}$ & Other countries & Amount enclosed \\
\hline ' & 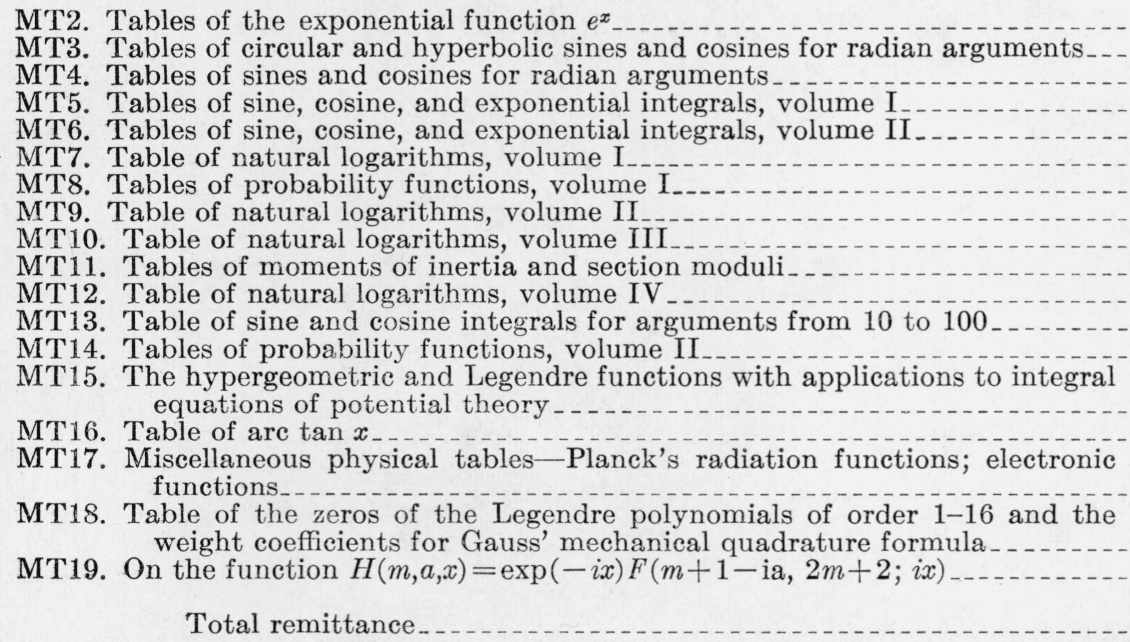 & $\begin{array}{l}\$ 2.00 \\
2.00 \\
2.00 \\
2.00 \\
2.00 \\
2.00 \\
2.00 \\
2.00 \\
2.00 \\
2.00 \\
2.00 \\
2.00 \\
2.00 \\
2.00 \\
2.00 \\
1.50 \\
\\
.25 \\
.25\end{array}$ & $\begin{array}{r}\$ 2.50 \\
2.50 \\
2.50 \\
2.50 \\
2.50 \\
2.50 \\
2.50 \\
2.50 \\
2.50 \\
2.50 \\
2.50 \\
2.50 \\
2.50 \\
2.50 \\
2.50 \\
1.75 \\
\\
.30 \\
.30\end{array}$ & \begin{tabular}{|c} 
\\
\hdashline \\
\end{tabular} \\
\hline
\end{tabular}

1 Remittance should be in form of post-office money order, or check, and made payable to the order of the "National Bureau of Standards" in United States currency,

Send to

Number and Street.

City and State 


\section{MATHEMATICAL TABLES}

Attention is invited to a series of publications prepared by the Project for the Computation of Mathematical Tables conducted by the Federal Works Agency, Work Projects Administration for the City of New York, under the sponsorship of the National Bureau of Standards. The tables which have been made avail able through the National Bureau of Standards are listed below.

There is included in this list a publication on the hypergeometric and Legendre functions (MT15), prepared by the Bureau.

MT1. Table or the First Ten Powers or the Integers From 1 to 1000:

(1938) VIII + 80 pages; heavy paper cover. Out of print.

MT2. Tablas of the Exponential Function $e^{x}$.

The ranges and intervals of the argument and the number of decimal places in the entries are given below:

Range of $x$
-2.5000 to 1.0000
1.0000 to 2.5000
2.500 to 5.000
5.00 to 10.00

Interval of $x$
0.0001
.0001
.001
.01

Decimals given
18
15
15
12

(1939) XV+535 pages; bound in buckram, $\$ 2.00$.

MT3. Tables or Circular and Hyperbolic Sings and Cosings por Radian Argument8:

Contains 9 decimal place values of $\sin x, \cos x, \sinh x$ and $\cosh x$ for $x$ (in radians) ranging from 0 to 2 at intervals of 0.0001 .

(1939) XVII+ 405 pages; bound in buckram, $\$ 2.00$.

MT4. Tables of Sines and Cosings por Radian Arguments:

Contains 8 decimal place values of sines and cosines for radian arguments ranging from 0 to 25 at intervals of 0.001 .

(1940) XXIX + 275 pages; bound in buckram, $\$ 2.00$.

MT5. Tables of Sine, Cosine, and Exponential Integrals, Volume I:

Values of these functions to 9 places of decimals from 0 to 2 at intervals of 0.0001 .

(1940) XXVI+444 pages; bound in buckram, $\$ 2.00$.

MT6. Tables of Sine, Cosine, and Exponential Integrals, Volume II:

Values of these functions to 9,10 , or 11 significant figures from 0 to 10 at intervals of 0.001 , with auxiliary tables.

(1940) XXXVII + 225 pages; bound in buckram, $\$ 2.00$.

\section{MT7. Table of Natural Logarithms, Volumb I:}

Logarithms of the integers from 1 to 50,000 to 16 places of decimals.

(1941) XVIII+501 pages; bound in buckram, $\$ 2.00$.

MT8. Tables or Probability Functions, Volumb I:

Values of these functions to 15 places of decimals from 0 to 1 at intervals of 0.0001 and from 1 to 5.6 at intervals of 0001 .

(1941) XXVIII+302 pages; bound in buckram, $\$ 2.00$.

[Continued on p. 4 of cover》 
MT9. Tablx or Natural Logarithme, Volume II:

Logarithms of the integers from 50,000 to 100,000 to 16 places of decimals.

(1941) XVIII + 501 pages; bound in buckram, $\$ 2.00$.

MT10. Table of Natural Logarithm, Volume III:

Logarithms of the decimal numbers from 0.0001 to 5.0000 , to 16 places of decimals.

(1941) XVIII + 501 pages; bound in buckram, $\$ 2.00$.

MT11. Tablzs of thr Moments of Intrtia and Srction Moduli of Ordinary Angles, Chan nels, and Bulb Anglzs With Certain Platb Combinations:

(1941) XIII+197 pages; bound in green cloth, $\$ 2.00$.

MT12. Table of Natural Logarithms, Volume IV:

Logarithms of the decimal numbers from 5.0000 to 10.0000 , to 16 places of decimals.

(1941) XXII+ 506 pages; bound in buckram, $\$ 2.00$.

MT13. Tari a or Sing and Cosine Intrgrals por Arguments From 10 to 100:

(1942) XXXII+185 pages; bound in buckram, $\$ 2.00$.

MT14. Tables or Probability Functions, Volume II:

Values of these functions to 15 places of decimals from 0 to 1 at intervals of 0.0001 and from 1 to 7.8 at intervals of 0.001 .

(1942) XXI+344 pages; bound in buckram, $\$ 2.00$.

MT15. The hypergeometric and Legendre functions with applications to integral equations of potential theory. By Chester Snow, National Bureau of Standards. Reproduced from original handwritten manuscript.

(1942) VII+319 pages; bound in heavy paper cover, $\$ 2.00$.

MT16. TABLE OP ArC TAN X:

Table of inverse tangents for positive values of the angle in radians. Second central differences are included for all entries.

\begin{tabular}{|c|c|}
\hline Range of $x$ & $\begin{array}{l}\text { Interval between } \\
\text { successive arguments }\end{array}$ \\
\hline 0 to & 0.001 \\
\hline 7 to & .01 \\
\hline 50 to & .1 \\
\hline 300 to 2,000 & 1 \\
\hline, 000 to 10,000 & 10 \\
\hline
\end{tabular}

(1942) XXV+169 pages; bound in buckram, $\$ 2.00$.

MT1\%. Miscellaneous Physical Tables:

Planck's radiation functions (Originally published in the Journal of the Optical Society of America, Pebruary 1940); and

Electronic functions.

(1941) VII + 58 pages; bound in buckram, $\$ 1.50$.

MT18. Table of the Zeros of the Legendre Polynomials of Order 1-16 and the Weight Coefficients for Gauss' Mechanical Quadrature Formula.

(Reprinted from Bull. Amer. Mathemical Society, October 1942.)

5 pages with cover. 25 cents.

MT19. On the Function $H(m, a, x)=\exp (-i x) F(m+1-i a, 2 m+2 ; i x)$; with table of the confluent hypergeometric function and its first derivative.

(Reprinted from Journal of Mathematics and Physics, December 1942.) 20 pages, with cover. 25 cents.

Payment is required in advance. Make remittance payable to the "National Bureau of Standards," and send with order, using the blank form facing page 3 of the cover.

The prices are for delivery in the United States and its possessions and in countries extending the franking privilege. To other countries the price of MT2 to MT16, inclusive, is $\$ 2.50$ each; MT17, \$1.75; MT18 and MT19, 30 cents each; remittance to be made payable in United States currency.

Copies of these publications have been sent to various Government depositories throughout the country, such as public libraries in large cities, and colleges and universities, where they may be consulted.

A mailing list is maintained for those who desire to receive announcements regarding new tables as they become available. 